\title{
Photoelectron Spectroscopy under Ambient Pressure and Temperature conditions
}

D. Frank Ogletree ${ }^{1}$, Hendrik Bluhm ${ }^{2}$, Eleonore B. Hebenstreit ${ }^{3}$ and Miquel Salmeron ${ }^{3,4}$

${ }^{1}$ Molecular Foundry, Materials Sciences Division, Lawrence Berkeley National Lab

${ }^{2}$ Chemical Sciences Division, Lawrence Berkeley National Lab

${ }^{3}$ Materials Sciences Division, Lawrence Berkeley National Lab

${ }^{4}$ Materials Science and Engineering Department, University of California Berkeley. Berkeley, California 94720 USA.

\begin{abstract}
We describe the development and applications of novel instrumentation for photoemission spectroscopy of solid or liquid surfaces in the presence of gases under ambient conditions or pressure and temperature. The new instrument overcomes the strong scattering of electrons in gases by the use of an aperture close to the surface followed by a differentially-pumped electrostatic lens system. In addition to the scattering problem, experiments in the presence of condensed water or other liquids require the development of special sample holders to provide localized cooling. We discuss the first two generations of Ambient Pressure PhotoEmission Spectroscopy (APPES) instruments developed at synchrotron light sources (ALS in Berkeley and BESSY in Berlin), with special focus on the Berkeley instruments. Applications to environmental science and catalytic chemical research are illustrated in two examples.
\end{abstract}

Key words: In situ electron spectroscopy, environmental science, catalysis 


\section{Introduction}

Chemical processes at vapor/solid and vapor/liquid interfaces play a major role in such diverse fields as environmental and atmospheric science, heterogeneous catalysis, and tribology. To advance the science and develop applications in these fields it is important to obtain a detailed knowledge of the atomic scale geometrical and electronic structure of the interfaces as close as possible to real operating conditions of pressure and temperature. For example, the metal-oxygen phase diagram is well known for bulk materials, but is not known at the surface. Strong interactions with the oxygen gas and also with impurity or contaminant gases can completely change the surface stoichiometry, even when the bulk material is in a well defined phase. A host of phenomena including reactions in heterogeneous catalysis may depend on structures that are only stable in equilibrium with the high chemical potential of reaction gases, and this that cannot be duplicated by by cooling (to maintain a high surface coverage of adsorbates) to low pressures. Another key difficulty is that the kinetics leading to equilibrium slow down by orders of magnitude, often making it impossible to achieve the true thermodynamic equilibrium state. Thus the surface structure of materials over entire regions of the P-T phase diagram are missed when experiments are not performed in equilibrium at relevant gas pressures. As a figure of merit, between $10^{-8}$ and $100 \mathrm{~Pa}$, the gas-phase chemical potential of $\mathrm{O}_{2}$ changes by $0.30 \mathrm{eV} /$ atom at 300 $\mathrm{K}$, or $0.58 \mathrm{eV} /$ atom at $600 \mathrm{~K}$.

Over the past decades a number of surface-sensitive techniques have been used under elevated (>100 Pa) pressures, among them infrared spectroscopy ${ }^{1,2}$, sum-frequency generation $(\mathrm{SFG})^{3,4,5,6,7}$, near edge X-ray absorption fine structure (NEXAFS) ${ }^{8}$, neutral-impact collision ion scattering spectroscopy $(\text { NICISS })^{9}$, meta-stable impact electron spectroscopy (MIES) $)^{10,11}$, scanning force microscopy ${ }^{12,13,14}$, scanning tunneling microscopy ${ }^{15,16}$ and scanning electron microscopy ${ }^{17}$. One of the most versatile analytical techniques for probing the composition and electronic structure of surfaces is X-ray photoemission spectroscopy (PES). PES allows the quantitative analysis of the surface composition and provides information about the chemical state of elements via the detection of "chemical shifts" in the binding energy (BE) of the photoelectrons. The nm-scale mean free path of electrons with kinetic energies $(\mathrm{KE})<1500 \mathrm{eV}$ in a solid or liquid makes PES a strongly surface-sensitive method. The same strong scattering of electrons by gas molecules, however, hinders the application of PES to measurements under gas atmospheres at pressures $>10^{-3} \mathrm{~Pa}$, and for that reason PES is conventionally performed under high-vacuum conditions. 
In order to perform PES experiments at pressures $>10^{-3} \mathrm{~Pa}$, the attenuation of the electrons due to scattering by gas molecules has to be kept at a minimum by minimizing the path length of the electrons in the high-pressure region. This can be achieved by placing the sample inside a reaction chamber and bringing the sample surface close to a differentially-pumped aperture, behind which the pressure drops by several orders of magnitude. This basic concept has been used in all ambient pressure PES setups developed over the past forty years, starting with the designs by Kai Siegbahn and coworkers in the late 1960's, which were initially used gas phase experiments. ${ }^{18}$ During the following years a number of new APPES setups were developed by Hans \& Kai Siegbahn and coworkers, in particular for the investigation of liquid/vapor interfaces. ${ }^{19}$ This poses additional challenges, because stable and clean liquid surfaces need to be prepared inside a vacuum chamber. The Uppsala group overcame this problem by using wires ${ }^{20}$, rotating trundles ${ }^{21},{ }^{22}$ and disks ${ }^{23,24}$ that continuously moved through a liquid reservoir and were coated by a thin liquid layer that was then investigated using PES. In addition, liquid jet sources were used. ${ }^{25}$ A number of other groups designed instruments in the 1970's for the investigation of liquids with low vapor pressures (<50 Pa) using ultraviolet photoelectron spectroscopy (UPS), e.g. Ballard et al. ${ }^{26,27}$ and Delahay et al. ${ }^{28,29,30}$ Roberts et al. ${ }^{31}$, Grunze et al. ${ }^{32}$, and Steinrück et al. ${ }^{33}$ developed APPES instruments of vapor/solid surfaces, in particular for the investigation of heterogeneous catalytic reactions. All aforementioned instruments use either X-ray cathodes or noble gas discharge lamps as photon sources, and are able to operate at pressures of about up to $100 \mathrm{~Pa}$ by using two or three differential pumping stages between the sample chamber and the electron analyzer.

A different approach for the investigation of liquids with high vapor pressure was taken by Winter and Faubel et al., who perform PES on liquid microjets with jet diameters below $10 \mu \mathrm{m} .^{34,35}$ The jets were expanded into a measurement chamber with a working pressure of $10^{-3} \mathrm{~Pa}$, where the scattering of electrons by gas phase molecules was negligible. The limitation of this approach is that the liquid surface is not in equilibrium with its vapor.

The pressure limit in APPES is determined on one hand by the attenuation of the electrons by gas molecules, and on the other hand by the pressure differential between the sample chamber and the electron analyzer, which needs to be kept under high vacuum. As will be discussed in detail below, the upper pressure limit in APPES experiments can be increased by decreasing the size of the first aperture, which improves differential pumping as well as reducing the path length of the electrons through the high-pressure region. Furthermore, by focusing the electrons onto the differentially-pumped apertures using electrostatic lenses in the pumping stages, differential pumping is obtained without significant loss 
of signal. This principle has been applied in a new generation of APPES instruments that are based at $3^{\text {rd }}$ generation synchrotrons. A prototype instrument that was developed at the Advanced Light Source in Berkeley in 1999 operates at the bending magnet beamline 9.3.2 at the ALS. ${ }^{36}$ The next generation of instruments was jointly developed a few years later by the Fritz Haber Institute (Berlin) and Lawrence Berkeley National Laboratory. These instruments, which use similar electrostatic lens systems, are running currently at the ISISS beamline at BESSY in Berlin ${ }^{37}$, and at beamline 11.0.2 at the ALS in Berkele $^{38}$. The high brightness $3^{\text {rd }}$ generation synchrotrons provides tightly-focused, intense $\mathrm{x}$-rays, which makes possible the use of small front aperture diameters (i.e. improved differential pumping) without loss of signal. The combination of a differentially-pumped electrostatic lens system with a synchrotron light source led to a significant increase of the pressure limit in APPES.

\section{Fundamentals of the operation of APPES}

All modern instruments for electron spectroscopy are based on electrostatic energy analyzers and electron counting detectors operating in high vacuum. Short of a revolutionary advance in detector technology, such as the development of solid-state electron detectors with meV resolution, APPES will be performed with vacuum spectrometers separated from the higher-pressure gas environment sample region by apertures. The diameter $D_{0}$ of the primary aperture sets the fundamental scale for the experiment. If the sample is too close to the aperture, the gas environment at the sample surface is strongly perturbed, while if the sample is too far the photoemission signal is attenuated by electronmolecule scattering. In practice the optimum sample distance is a few times $\mathrm{D}_{\mathrm{o}}$. Since the electron mean free path $\lambda_{\text {gas }}(\sim 1 \mathrm{~mm}$ at $100 \mathrm{~Pa}$ and room temperature for water) is inversely proportional to pressure, the aperture size determines the maximum gas pressure $P_{\max }$, which scales as $\mathrm{D}_{\mathrm{o}}{ }^{-1}$.

Reducing the aperture size increases the working pressure, but it also reduces the photoemission signal as $\mathrm{P}_{\max }{ }^{2} \sim \mathrm{D}_{\mathrm{o}}^{-2}$ unless the incident $\mathrm{x}$-ray flux can be increased in proportion. This may be possible with a bright synchrotron source, but then radiation damage to the sample will increase as $\mathrm{D}_{0}^{-2}$ unless mitigated by translating or renewing the sample during the experiment. As $D_{0}$ is reduced, increased precision is required to place the sample near the aperture and to align the incident $\mathrm{x}$-ray beam. The gas load on the differential pumping system scales as $\mathrm{P}_{\max } \mathrm{D}_{\mathrm{o}}{ }^{2} \sim \mathrm{P}_{\max }{ }^{-1}$, so reducing the aperture size to achieve higher working pressures simplifies the design of the pumping system. 
The second-generation APPES-2 system at the Advanced Light Source (ALS), described in detail below, has been used with $300 \mu \mathrm{m}$ or larger apertures to date, limiting the practical working pressure to $\sim 1000 \mathrm{~Pa}$. With only modest hardware changes the aperture size can be reduced to $\sim 15 \mu \mathrm{m}$, on the order of the X-ray spot size that can be obtained at ALS beamline 11.0.2, which would increase the working pressure to $\sim 20 \mathrm{kPa}(0.2$ bar $)$.

It is possible to imagine a third-generation nano-APPES-3 system using sub-micron apertures that could operate at pressures of several bar. Micro-fabricated apertures in metallized silicon nitride pyramids of $\sim 100 \mathrm{~nm}$ are commercially available for use in scanning near-field optical microscopy. ${ }^{39}$ Scanning transmission $\mathrm{X}$-ray microscopes ${ }^{40}$ based on zone plates have obtained spot sizes $\sim 15 \mathrm{~nm}^{41}$ and use vacuum-compatible nano-translation stages with few-nm positioning accuracy. A scanning electron microscope could be used to align the nano-APPES system under vacuum conditions before admitting the reaction gasses. With a sub-micron aperture, the gas flow into the electron spectrometer would be negligible, and a special differential pumping system would no longer be required.

\section{Electron-Gas Interactions}

Photoelectrons can interact elastically or inelastically with gas molecules. Elastic scattering changes the direction but not the energy of photoelectrons. The effects of elastic scattering depend on the experimental geometry. If the area of the sample illuminated by $x-$ rays is large compared to the aperture $\mathrm{D}_{\mathrm{o}}$, the net effect of elastic scattering will be small - some electrons will be scattered out of the spectrometer acceptance angle, and other electrons will be scattered in. On the other hand, if the x-ray spot is small, then elastic scattering

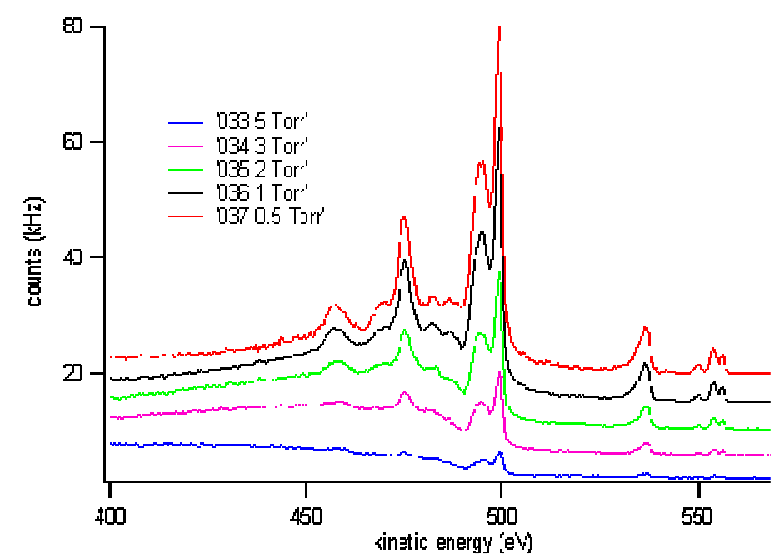
will reduce the intensity of the experimental spectrum without modifying the energy distribution. The elastic scattering distribution is peaked in the forward direction, so small-angle elastic events will have little effect on the sample-spectrometer transmission, and the net effect of elastic scattering may be somewhat smaller than the integrated cross-section would suggest.

Inelastic scattering events include excitation of internal molecular electronic, vibrational, or rotational states and ionization or fragmentation of the molecules. Inelastic scattering obscures the sample photoemission spectrum. Figure 1 shows the evolution of a gas-phase APPES spectrum of water 
vapor with pressure. At low pressure, the photoemission peaks from the highest few occupied molecular orbitals and the Auger KLL peaks are clearly resolved. As pressure increases, the original peaks are attenuated and the inelastically scattered background increases significantly.

Molecular ionization is the dominant energy-loss mechanism for electrons with kinetic energy greater than a few times the ionization threshold, which is typically $\sim 10 \mathrm{eV}$. Garcia and coworkers have studied electron-molecule scattering in great detail. Figure 2, reproduced from their work, ${ }^{42}$ shows the experimental electron energy loss distribution for electronimpact scattering from gas-phase $\mathrm{H}_{2} \mathrm{O}$. The minimum energy transfer is $6.2 \mathrm{eV}$, corresponding to a HOMO-LUMO electronic excitation, and the excitation probability increases significantly above the ionization threshold. The energy distribution peaks at about $20 \mathrm{eV}$, approximately twice the ionization energy, so significant numbers of $\sim 10 \mathrm{eV}$ secondary electrons are produced. These gas-phase secondary electrons

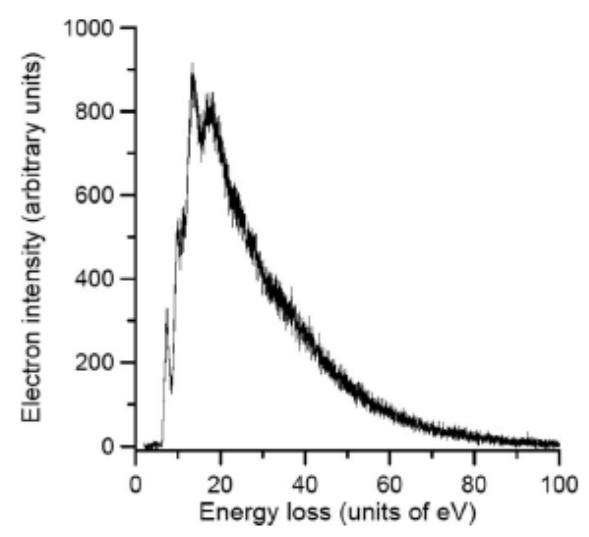
play a useful role in compensating surface charging during APPES experiments on insulating samples.

The electron mean-free path in a gas atmosphere is $\lambda_{\text {electron }}=k_{B} \cdot T / P \cdot \sigma_{\text {electron }}$ where $\sigma_{\text {electron }}$ is the electron-molecule scattering cross-section. Equating the mean-free path with the aperture diameter gives an estimate for the maximum working pressure $P_{\max }=k_{B} \cdot T / D_{o} \cdot \sigma_{\text {electron }}$. Figure 3 shows published energy-dependent scattering cross-sections for two small molecules, water and toluene, and

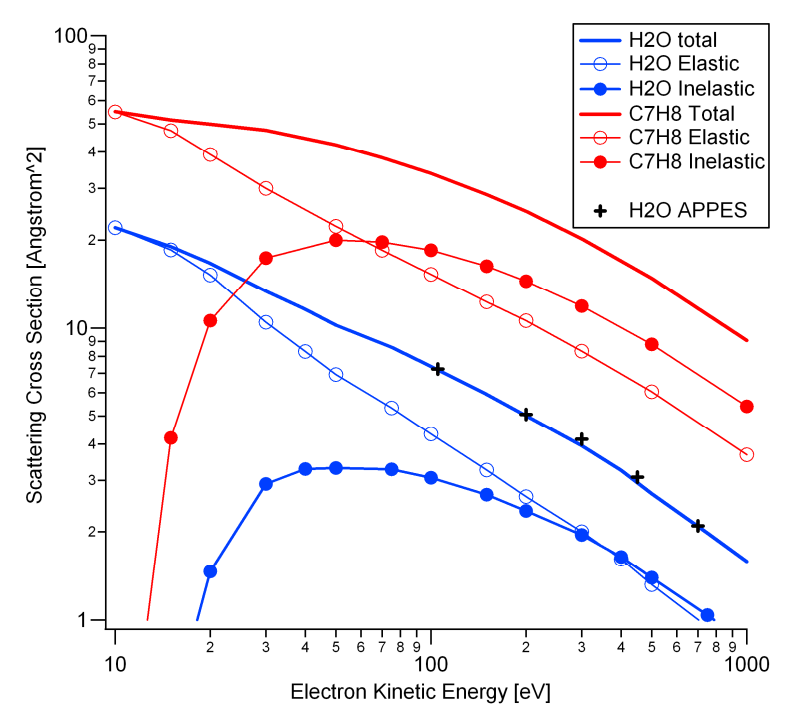

experimental measurements made on our APPES system. The elastic scattering cross-sections tend to decrease monotonically approximately as $K E^{-\alpha}$ with $\alpha$ $\sim 0.5-0.75$. The inelastic cross-section rises rapidly above the molecular ionization threshold, with a broad plateau between a few tens and a few hundreds of $\mathrm{eV}$, the most interesting energy region for synchrotron APPES since this maximizes surface sensitivity. Toluene, with 36 valence electrons, has significantly stronger scattering than water, with 8 valence electrons. 
The experimental measurements shown figure 3 were made by placing a graphite (HOPG) crystal $0.9 \mathrm{~mm}$ from the $300 \mu \mathrm{m}$ aperture of our APPES spectrometer. The C 1s peak area was measured as a function of water vapor pressure between zero and $665 \mathrm{~Pa}$ for photoelectron kinetic energies between 100 and $700 \mathrm{eV}$ (incident $\mathrm{x}$-ray energies between 390 and $990 \mathrm{eV}$ ). Water should not adsorb on the hydrophobic HOPG surface, so the attenuation is due to electron-gas scattering. The C1s peak areas decreased exponentially with gas pressure. The effective scatterings cross-sections, shown by crosses, are a good fit to the independently-measured values ${ }^{42}$ if the effective path length for the photoelectrons is $1.1 \mathrm{~mm}$, somewhat larger than the $0.9 \mathrm{~mm}$ sample-aperture separation.

Using the total scattering cross sections, with an aperture $\mathrm{D}_{\mathrm{o}}$ of 300 micrometers, $\mathrm{P}_{\max }$ for water is $220 \mathrm{~Pa}$ at $100 \mathrm{eV}$ kinetic energy, or $\sim 500 \mathrm{~Pa}$ at $500 \mathrm{eV}$. For toluene the limits would be $\sim 40 \mathrm{~Pa}$ at 100 $\mathrm{eV}$ and $\sim 95 \mathrm{~Pa}$ at $500 \mathrm{eV}$. These limits are not absolute - spectra can be obtained even at several times $\mathrm{P}_{\max }$, but the signal to noise ratio is reduced and acquisition times are increased.

\section{Photon-Gas Interactions}

The scattering of $\mathrm{x}$-ray photons by the reaction gases in APPES experiments is generally much weaker than for electrons. The electron-gas cross sections shown in fig 3 are several $\AA^{2}$, while the x-ray scattering cross-sections for the $1 s$ levels of light elements like $\mathrm{C}, \mathrm{N}, \mathrm{O}$ and $\mathrm{H}$ are about three orders of magnitude smaller, as shown in figure 4. Even though the x-ray path length may be one or two orders of magnitude greater than the electron path length due to constraints of experimental geometry, gas-phase $\mathrm{x}$-ray attenuation is generally a secondary effect compared to photoelectron attenuation.

There is an exception in the case of NEXAFS experiments on atoms which are present in both the gas-phase and the condensed sample, such as $\mathrm{O}$ when studying oxidation or water absorption. In this experiment APPES spectra are recorded as the x-ray energy sweeps through the atomic absorption edge, and resonant gas-phase absorption can strongly modulate the x-ray flux arriving at the sample, requiring deconvolution from the experimental

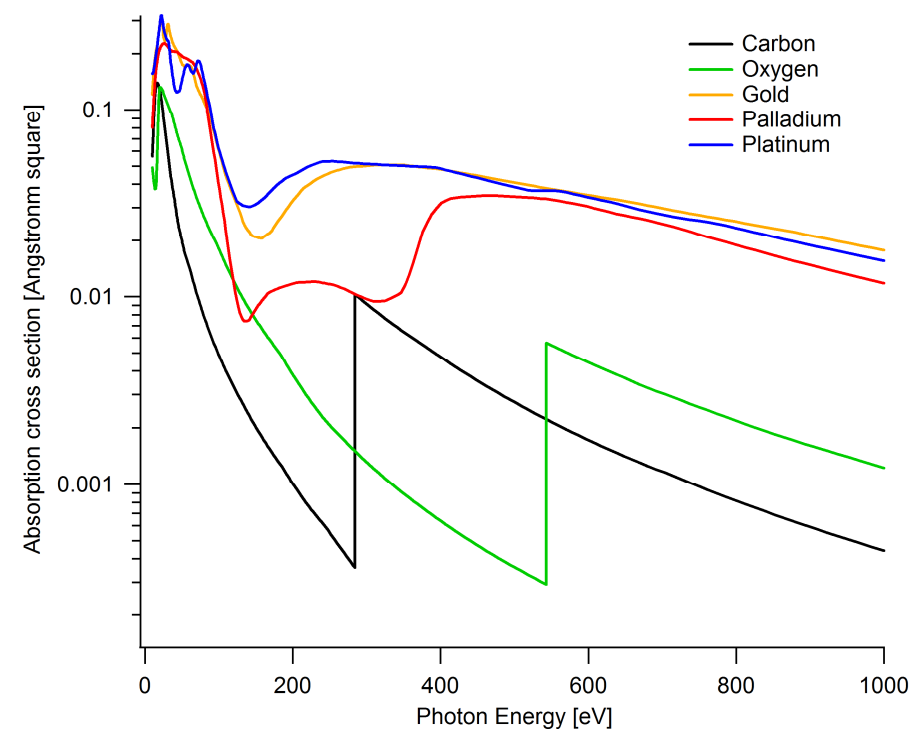




\section{NEXAFS spectra.}

It is straightforward to obtain data on the gas-phase absorption directly since the APPES system is also well-suited for gas-phase photoemission studies. As described below, the photon flux available is $10^{12} \mathrm{~s}^{-1}$ at a resolution of $100 \mathrm{meV}$ or better. So for an $\mathrm{x}$-ray absorption cross section of $\sim 5 \cdot 10^{-23} \mathrm{~m}^{2}$, as for $\mathrm{O} \sim 100 \mathrm{eV}$ above its absorption edge, and an x-ray path length in front of the APPES aperture of $100 \mathrm{um}$, the rate of absorption is $\sim 2 \cdot 10^{6} \mathrm{~Pa}^{-1} \mathrm{~s}^{-1}$. If the APPES analyzer accepts a half-angle of $0.1\left(5.7^{\circ}\right)$ with a transmission of $\sim 10 \%$, this gives a count rate of $\sim 200 \mathrm{~Pa}^{-1} \mathrm{~s}^{-1}$. This sensitivity means that during catalytic APPES experiments, the partial pressure of reactants and products in front of the sample can be directly measured. For calibration purposes, the sample can be retracted and the x-ray beam can be placed very close to the APPES aperture to minimize electron-gas scattering, then pure gas-phase spectra can be recorded as a function of pressure.

Gas phase X-ray absorption has another consequence; the ionization of gas molecules provides a local source of electrons for surface charge compensation during experiments on insulating samples. In the example above, the gas ionization current is $\sim 100 \mathrm{uA} / \mathrm{m}^{2} \mathrm{~Pa}$. This is fortunate since electron or ion guns, which are typically used for charge compensation in XPS, are not practical in the APPES environment. At high gas pressures with strongly focused x-rays, gas molecular ions and radicals may be generated in sufficient number to modify the surface chemistry.

\section{Gas flow and differential pumping}

Different regimes of gas flow are described by the ratio of the mean-free path for moleculemolecule collisions, $\lambda_{\text {gas }}$, to the characteristic dimension of the system, $D_{o}$ in the case of APPES. When this ratio, known as the Knudsen number, is large, molecule-molecule collisions can be neglected, and gas dynamics are described as molecular flow, the typical case for high vacuum. When this ratio is small, gas flows as a viscous fluid. In the intermediate or Knudsen regime, analytical description is difficult since the detailed properties of the system enclosing the gas become important. The gas mean free path is $\lambda_{\text {gas }}=k_{B} \cdot T / \sqrt{2} \cdot P \cdot \sigma_{\text {gas }}$ where $\sigma_{\text {gas }}$ is the cross section for molecule-molecule scattering, which is approximately the $2 / 3$ power of the molecular volume in its condensed liquid phase. At the limits of APPES working pressure, where $\lambda_{\text {electron }} \sim \mathrm{D}_{\mathrm{o}}$, the Knudsen number

$K_{n} \approx \lambda_{\text {gas }} / \lambda_{\text {electron }} \approx \sigma_{\text {electron }} / \sigma_{\text {gas }}$. For water, $\sigma_{\text {gas }} \sim 10 \AA^{2}$, so for electrons at $100 \mathrm{eV}, \mathrm{K}_{\mathrm{n}} \sim 1$ and at $1 \mathrm{keV}$, $\mathrm{K}_{\mathrm{n}} \sim 6$. Therefore molecular flow should give a good qualitative description of APPES but quantitative predictions may off in the high pressure limit. 
In the molecular flow limit, pressure is reduced in the vicinity of the aperture proportional to the solid angle subtended by the aperture, provided the thickness of the aperture is small compared to $\mathrm{D}_{\mathrm{o}}$. Along the axis of the aperture, the effective pressure $P(z)=P_{o}\left(\frac{1}{2}-z / \sqrt{D_{o}^{2}+4 \cdot z^{2}}\right)$ where $\mathrm{z}$ is zero in the aperture plane and positive on the vacuum side. ${ }^{36}$ If the sample is placed close to the aperture, the pressure at the sample surface will be less than $P_{o}$, but the effect of the aperture drops off rather quickly. To minimize sample perturbation by the aperture, the aperture-sample distance should be $>2 \mathrm{D}_{0}$. This is particular important for equilibrium experiments - for ice near the freezing point, the residence time of a molecule on the surface is $\sim 1 \mu \mathrm{s}$, so even a slight reduction in the local pressure by the aperture cone will quickly melt a hole in the sample surface. Experimentally, when the sample is too close to the aperture, the gas flow is reduced, and the pressure drops in the first differential pumping stage. For a photoelectron traveling through a thin aperture, the effective path length for electron scattering is $L_{e f f}(z)=\frac{1}{P_{o}} \int_{z}^{\infty} P(x) d x$. At $2 \mathrm{D}_{\mathrm{o}}, L_{e f f}=2.03 \mathrm{D}_{\mathrm{o}}$, approximately the geometrical distance, while the effective path length from the aperture plane is only $1 / 4 \mathrm{D}_{0}$, so there is little to be gained by schemes to separate the electron trajectory from the gas jet exiting the aperture. In the case of viscous flow, the aperture forms a supersonic jet, and the gas flow and effective path length depend on the internal degrees of freedom of the gas molecules. In the case of water, the pressure in the aperture plane would be 0.63 rather than 0.5 , and the effective path length from the aperture plane would be 0.51 rather than $0.25 \mathrm{D}_{\mathrm{o}} .{ }^{36}$ The experimental measurements for APPES-2 shown in Fig 3 found an effective path length of $3.7 \pm 0.3 \mathrm{D}_{\mathrm{o}}$ for a geometrical separation of $3 \mathrm{D}_{\mathrm{o}}$. The excess path length of $0.7 \pm 0.3 \mathrm{D}_{\mathrm{o}}$ is probably due to the finite thickness of the aperture wall.

The flux through the differential pumping aperture in molecular flow is $\Phi_{m}=\frac{\pi}{16} D_{o}{ }^{2} \bar{v} \cdot P_{o}$ where $\bar{v}$ is the average molecular velocity. For water at room temperature with a $300 \mu \mathrm{m}$ aperture at a pressure of 1 $\mathrm{kPa}$, this is $4.25 \mu \mathrm{mol} / \mathrm{s}$ or $6.14 \mathrm{sccm}$. It is difficult to get an actual conductance-limited pumping speed larger than $\sim 100 \mathrm{l} / \mathrm{s}$ in a typical UHV system, so this produces a pressure of $\sim 0.1 \mathrm{~Pa}\left(10^{-1} \mathrm{~Pa}\right)$ after the aperture, so one or more differential pumping stages is required. (In contrast, for a sub-micron aperture with a 1 bar source pressure, the mass flow would be $~ 1000$ times smaller, and pumping the input lens of a conventional hemispherical analyzer should be sufficient.)

There are two contributions to the mass flow through the differential pumping system and into the analyzer. The first is the ballistically transported flux of un-scattered molecules $k \cdot P_{o} \cdot \pi \beta_{x}^{2}$, where $\beta_{x}$ is 
the half-angle of the differential pumping exit aperture seen from the source aperture. The constant $k$ is 1 for molecular flow, and 3.4, 2.2 or 1.7 for viscous supersonic flow with atomic, linear molecular or nonlinear molecular gases, respectively. The second contribution, which can be made negligible in a welldesigned system, is from the background of scattered gas molecules that are not removed by differential pumping. This places a limit on the angular transmission of the differential pumping system $\alpha_{x} \leq \sqrt{\frac{P_{a} \cdot S_{a}}{\pi \cdot k \cdot \Phi_{m}}}$ where $P_{a}$ is the analyzer pressure and $S_{a}$ is the analyzer pumping speed. Taking $P_{a} \sim$ $10^{-5} \mathrm{~Pa}$ and for $S_{a} \sim 50 \mathrm{l} / \mathrm{s}$ (since it is difficult to effectively pump a hemispherical analyzer), in the case of water vapor given above, $\beta_{x}<0.004\left(0.22^{\circ}\right)$.

\section{Electron Optics for APPES}

Reducing $\beta_{x}$ is required for differential pumping but also reduces the electron flux. A typical hemispherical analyzer input lens in small-spot mode can accept a half-angle $\alpha_{\text {lens }}$ of around 0.125 $\left(8^{\circ}\right){ }^{43}$ A passive differential pumping system will reduce the photoemission signal by a factor of $\left(\frac{\beta_{x}}{\alpha_{\text {lens }}}\right)^{2}$ or more than three orders of magnitude compared to a vacuum analyzer. Therefore we introduced the active differentially-pumped electron input lens with cross-overs at the pumping apertures. ${ }^{36}$ With this approach we are free to independently optimize the pumping and electron optics, thereby increasing APPES performance by at least two orders of magnitude compared to passive systems.

A conventional XPS energy analyzer consists of an input lens and a hemisphere. The energy resolution of the hemisphere $\frac{\Delta E}{E}=\frac{w_{\text {in }}+w_{\text {exit }}}{R_{\text {sphere }}}+\frac{1}{2} \alpha_{\text {sphere }}^{2}$ where $R$ is the radius of the energy analyzer, the w's are the widths of entrance and exit slits, and $a_{\text {sphere }}$ is the half-angle of the analyzer, typically $\sim 0.05$ $\left(3^{\circ}\right)$. The job of the input lens is to define the analysis area and angular acceptance at the sample $\left(w_{\text {lens }}\right.$, $\left.\alpha_{l e n s}\right)$ and image this onto the entrance slits, and also to decelerate the electrons to the hemisphere pass energy, subject to the condition $w_{\text {lens }} \alpha_{\text {lens }} \leq w_{\text {in }} \alpha_{\text {sphere }} \sqrt{\frac{E_{\text {pass }}}{K E}} \cdot{ }^{44}$ At a working distance of $2 \mathrm{D}_{\mathrm{o}}$, the maximum half-angle allowed by the APPES input aperture is $0.24\left(14^{\circ}\right)$. Since the analysis area $\mathrm{D}_{\mathrm{o}}$ is 
usually small compared to the hemisphere entrance slit width, the APPES lens will benefit from a high angular transmission.

\section{APPES Instrumentation}

Two systems for APPES have been constructed at the ALS. A prototype system was built first at bending magnet beamline 9.3 .2 to prove the concept of the differentially pumped electron lens. ${ }^{36}$ In this system the APPES-1 module was inserted into an existing vacuum system and coupled to an unmodified hemispherical energy analyzer through its input lens. This system demonstrated the utility of synchrotron APPES on problems of environmental chemistry ${ }^{45}$ and catalysis ${ }^{46}$, however experiments were relatively difficult to perform due to the limited sample manipulation and lack of tools for sample transfer or in-situ preparation other than heating in controlled gas environments. A second-generation APPES-2 system was constructed at the ALS undulator beamline 11.0.2, the Molecular Environmental Science beamline ${ }^{38}$, where the sample preparation, manipulation, $x$-ray and electron optics were optimized. Later, the 9.3.2 system was upgraded with improved sample preparation and manipulation capabilities.

Today, after successfully proving the usefulness of the technique, several synchrotron facilities are incorporating APPES instrumentation to attend the rapidly increasing number of users in the environmental, catalysis and other areas. Commercial manufacturers are also working on the development of stand alone APPES instruments with fixed energy x-ray sources. In this overview however we focus only on the second generation instrument, the APPES-2 in beamline 11.0.2.

\section{APPES-2 at the ALS}

The APPES-2 system has four major components: the x-ray source, the differentially-pumped electron spectrometer, the experimental vacuum system and the sample manipulation system. ALS beamline 11.0.2 is equipped with an elliptically polarized undulator capable of producing x-rays between 75 and $2400 \mathrm{eV}$. Above $160 \mathrm{eV}$ the x-ray polarization can be fully controlled (linear or circular) for structural or dichroism studies. The deflection and focusing of the final Kirkpatrick-Baez mirror pair are computer controlled and can produce a spot size at the sample as small as 7x10 $\mu \mathrm{m}$. The focused spot can be scanned over an area greater than $1 \mathrm{~mm}^{2}$, which is quite important in aligning the experiment, since the $\mathrm{x}$-ray spot must illuminate the sample along the axis of the electron spectrometer. 
When the sample-aperture separation is changed for experimental reasons, the x-ray source must be realigned with a precision of a fraction of the aperture size $D_{0}$.

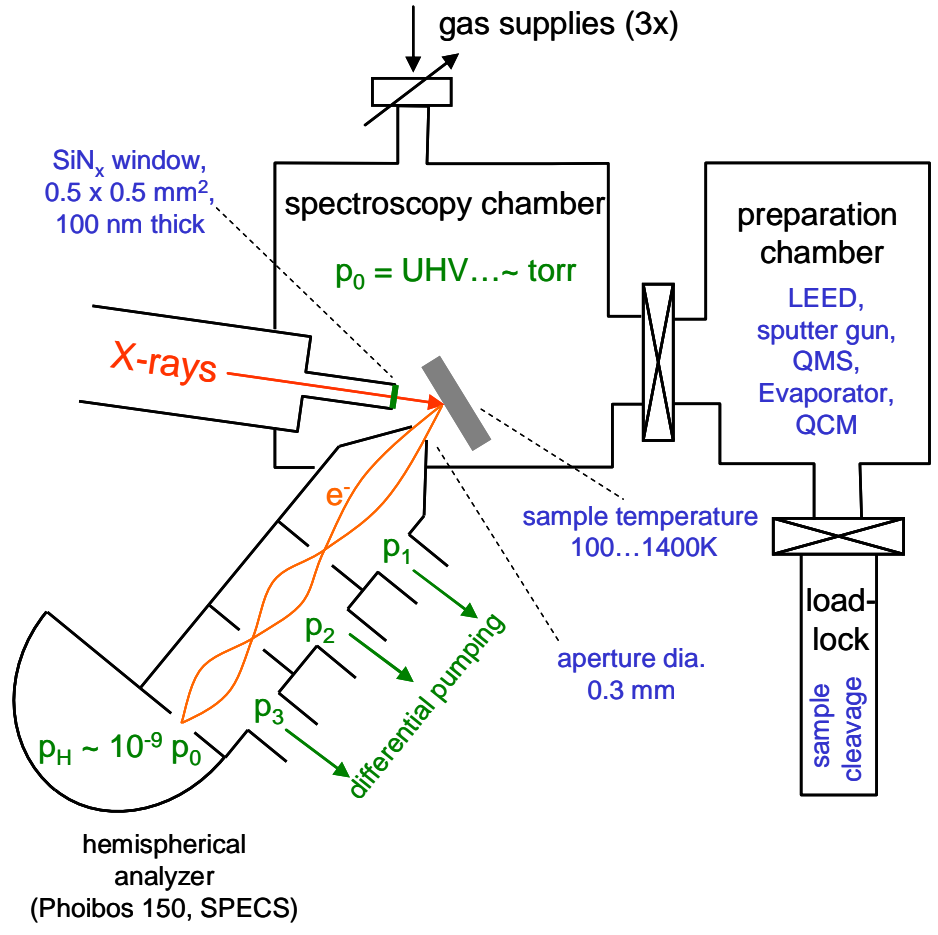

The $\mathrm{x}$-ray source is separated from the APPES reaction chamber by a thin window, typically $0.5 \mathrm{~mm}$ wide and $100 \mathrm{~nm}$ thick, of low-stress $\mathrm{SiN}_{\mathrm{x}}{ }^{47}$ The lateral size of the window allows the $\mathrm{x}$-ray source to be scanned for alignment with the sample and analyzer. The window is mounted on a small metal tube in an UltraTorr fitting for quick exchange. The window-sample separation is typically 5 to $30 \mathrm{~mm}$, with smaller distances being selected for higher working pressures to minimize gas-phase $\mathrm{x}$-ray absorption. The measured $\mathrm{x}$-ray flux at the sample position is $>10^{13}$ photons/s from 200-400 eV, and >

$10^{11}$ photons/s from 400 to $800 \mathrm{eV}$, with energy resolution better than $100 \mathrm{meV}$. Between 800 and 1400 $\mathrm{eV}$ the flux drops monotonically by a factor of $\sim 40$.

The analyzer axis is $45^{\circ}$ from the $\mathrm{x}$-ray beam in the horizontal plane, and raised by $35^{\circ}$ above the horizontal (fig 5). This means that the angle between the polarization of the incident X-rays and the $\mathbf{k}$ vector of the electrons is $54.7^{\circ}$, the "magic" angle. The sample normal is typically the horizontal plane, but this geometry is compatible with a horizontal sample surface such as a free liquid film (the $\mathrm{x}$-ray beam descends by a $4^{\circ}$ degree angle as it leaves the beamline, the entire APPES system is tilted to accommodate this). When the experimental system is placed at the beamline, a manual strut system with 6 degrees of freedom is adjusted to position the analyzer aperture along the beam axis. The window assembly position is then optimized using a manual $x-y$ translation stage, and the final alignment is done with the $\mathrm{x}$-ray mirror.

The differentially-pumped electron spectrometer for the APPES-2 system uses a modified Specs Phoibos 150 hemispherical energy analyzer with 9 channeltron detectors. ${ }^{48}$ The first stage of the input lens of the spectrometer was replaced by a custom electron optics system, which was designed in collaboration with the Inorganic Chemistry Department of the Fritz Haber Institute. The detailed design 
and performance of the input lens are described in another publication. ${ }^{37}$ The Specs control electronics and software were customized to control the lens.

The APPES-1 lens performance was limited by its lack of magnetic shielding, and its small dimensions, which resulted in high-voltage breakdowns in the lens when at high working pressures. These problems were addressed in the APPES-2 design. The entrance aperture is a metal cone similar to the skimmer nozzle used in molecular beam experiments.

The first differential stage was pumped by a $7001 /$ s turbomolecular pump with a maximum gas throughput $>0.36 \mathrm{~Pa}-\mathrm{m}^{3} / \mathrm{s}(200 \mathrm{sccm})$. The second stage and the hemisphere were pumped 250 and 70 1/s turbo pumps. ${ }^{49}$ The turbo pumps were backed by a molecular drag pump followed by a membrane pump. ${ }^{50}$ The three-stage dry pumping system was capable of UHV performance and maintained a reasonable compression ratio for hydrogen. The second differential pumping stage was equipped with a quadrupole mass spectrometer ${ }^{51}$ that could be inserted into the electron lens to intercept the molecular beam from the sample (which blocked the photoelectrons), or retracted to monitor the reaction gases without interfering with the spectrometer performance. With a $0.6 \mathrm{~mm}$ initial aperture, high vacuum could be maintained in the electron energy analyzer at working pressures up to $10 \mathrm{kPa}(0.1 \mathrm{bar})$.

The vacuum system has a UHV sample preparation chamber equipped with a LEED/Auger optics for surface analysis; a sputter ion gun for sample cleaning; an evaporator and quartz crystal monitor for metal deposition; a residual gas analyzer (RGA) for thermal desorption spectroscopy; leak valves for gas introduction; and a plasma source for dosing the sample with gas ions or radicals. A magnetic transfer rod can move samples from the preparation chamber to the analysis chamber through a gate valve. A second magnetic transfer rod can move samples from a turbo-pumped airlock for sample introduction. The airlock includes a mechanism for sample cleavage. A needle valve connects the analysis chamber to the preparation chamber so the RGA can be used to monitor the analysis gas environment.

The analysis chamber has a volume of about 20 l. It is equipped with a variety of gas sources including electronically-controlled leak valves, mass-flow controllers, and a pressure-controlled chokedflow source for water vapor and other condensable liquids. A welded stainless-steel gas manifold and gas cabinet maintains the purity of reaction gasses, and allows experiments with toxic gasses (NO, CO). Pressure is monitored by capacitance manometers ${ }^{52}$ and by an ion gauge for high vacuum. The chamber is pumped by a turbomolecular pump, which is isolated by a gate valve during high-pressure experiments. The analysis chamber also has a turbo pump, and both chambers have a base pressure of better than $2 \times 10^{-8} \mathrm{~Pa}$ after bake-out. Ion pumps were not used to avoid problems with "memory" effects, 
where previously pumped gasses can be released from the pump during experiments. A variable bypass valve lets the analysis chamber act as a flow reactor and gives a reasonable time constant for pressure changes ( $30 \mathrm{~s})$. The system also has a video microscope to assist in positioning the sample near the aperture, and an electron gun that can be used in high vacuum for Auger spectroscopy and electron optics testing when x-rays are not available from the synchrotron.

\section{APPES-2 Sample manipulation}

Sample manipulation, heating and cooling are critical parts of the APPES experiment. Heating and cooling are more challenging than in a high-vacuum XPS experiment. For experiments with condensable gases near equilibrium, the sample must be the coldest part of the system - if another part of the sample manipulator is colder, gas will condense their instead. Heat transfer between the sample and gas molecules means that more heating and cooling power is required than in a vacuum environment. The APPES-2 system uses the commercial Thermionics STLC system. ${ }^{53}$ The samples are mounted on a 40 mm diameter Molybdenum plate with four independent electrical leads. A magnetically coupled linear translator ${ }^{54}$ pushes the plate against the manipulator dock and locks or unlocks a bayonet connection with a rotary motion. When the plate is locked to the dock, it is spring-loaded against the face of a copper cylinder several mm thick (fig 6), which is part of a reservoir that can be cooled by flowing gas or liquid, including liquid nitrogen. The independent electrical contacts are used for thermocouples or other temperature sensors, and to provide electrical power for sample heating. The sample heater is integrated into the plate, in direct contact with the sample, and different types of plate/heater assemblies can be used depending on the requirements of the experiment. One plate has a four-quadrant diode for xray metrology 55 that is used to measure $\mathrm{x}$-ray flux and beam profiles.

The sample dock in the analysis chamber is mounted on a $150 \mathrm{~mm}$ differentially-pumped rotary flange, which allows $360^{\circ}$ rotation with no relative motion of the electrical or cooling connections in vacuum. This is supported by an xyz manipulator with $100 \mathrm{~mm}$ of vertical travel and $\pm 15 \mathrm{~mm}$ of lateral motion. The sample face is on the manipulator rotation axis. All manipulator motions are driven by stepper-motors controlled from a LabView ${ }^{56}$ program, which allows for compucentric rotation of the sample in front of the input aperture and for automated sample scanning during APPES data acquisition to mitigate radiation damage. The sample positioning accuracy is better than $10 \mathrm{um}$. LabView programs also control sample heating and gas flow in the analysis chamber. The preparation chamber has a similar 
manipulator with the sample face offset from the rotation axis by $60 \mathrm{~mm}$. Rotary motion brings the sample to the different analytical and sample preparation instruments.

A sample plate with a ceramic "button heater" capable of reaching $1000^{\circ} \mathrm{C}$ in oxygen or $1200^{\circ} \mathrm{C}$ in vacuum $^{57}$ was used for metal single-crystal samples in catalytic experiments. ${ }^{58}$ A thermocouple was spot-welded to the sample to monitor temperature. The stray magnetic fields from the toroidally-wound resistive element in the button heater have a small positive or negative effect on signal intensity, depending on the polarity of the heater current. Some special precautions must be taken for highpressure catalytic experiments in oxidizing atmospheres. Many refractory metals such as Ta and Mo form relatively volatile oxides. Since the gas mean-free path is small compared to the sample dimensions, metal oxides can diffuse to the sample and adsorb, contaminating the surface. ${ }^{59} \mathrm{Ni}$ contamination was also observed from heating type-K thermocouples in oxygen. Therefore a heater with a stainless steel plate was used for high temperature experiments, and a Mo plate was used for experiments where cooling was critical due to its 40x higher thermal conductivity.

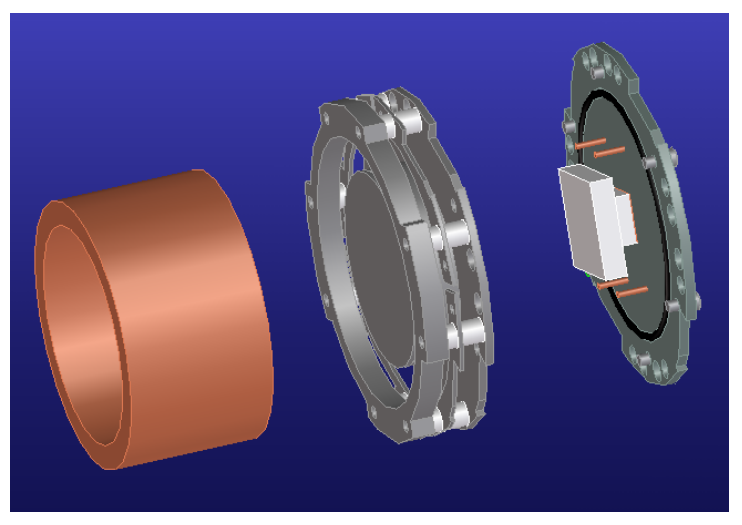

Another plate used an electron-bombardment heater ${ }^{60}$, which allowed for the fast annealing of samples at temperatures in excess of $1400 \mathrm{~K}$ in UHV at a typical sample bias of $+700 \mathrm{~V}$. Electron bombardment cannot be done above $\sim 1 \mathrm{~Pa}$ due to both oxidation of the filament and arcing (plasma breakdown) due to the high voltages applied to the sample holder. However, the tungsten filament that was mounted $\sim 0.5 \mathrm{~mm}$ behind the sample could be used for radiative and convective heating of the sample to moderate temperatures in non-oxidizing gas environments.

\section{Peltier sample holder}

We constructed a novel sample holder based on a thermoelectric Peltier cooler for experiments in condensing environments. Water-surface interactions are very important in environmental chemistry. ${ }^{61}$ The maximum water partial pressure is the vapor pressure of water or ice at the coldest point in the system. To avoid condensation on the chamber walls and other parts of the instrument, water pressure should be below $\sim 2 \mathrm{kPa}$ corresponding to $\sim 80 \%$ relative humidity at $20^{\circ} \mathrm{C}$. This makes the traditional "cold finger" approach to sample cooling impossible since condensation will occur on the cooling 
elements instead of the sample surface. The holder is constructed on a STLC plate with an o-ring sealed compartment containing a two-stage Peltier cooling element ${ }^{62}$ as seen in fig 6. A copper plug is set in a vacuum compatible polymer (Vespel) for thermal insulation and sealed to the stainless steel front plate of the plate assembly. The sample is mounted over the copper plug, completely covering it, by spring clips or glue. Four small electrical feedthroughs (fig 7) supply current to the Pelter cooler and connections for a thermocouple or thermistor internally attached to the copper plug. The hot side of the thermoelectric cooler is glued to the main body of the plate. When the front plate is screwed onto the plate base (fig 6), the copper plug makes contact with the cold side of the cooler. Indium foil shims are used to make a good thermal contact without applying excessive pressure to the thermoelectric element. This same holder can heat samples above ambient by

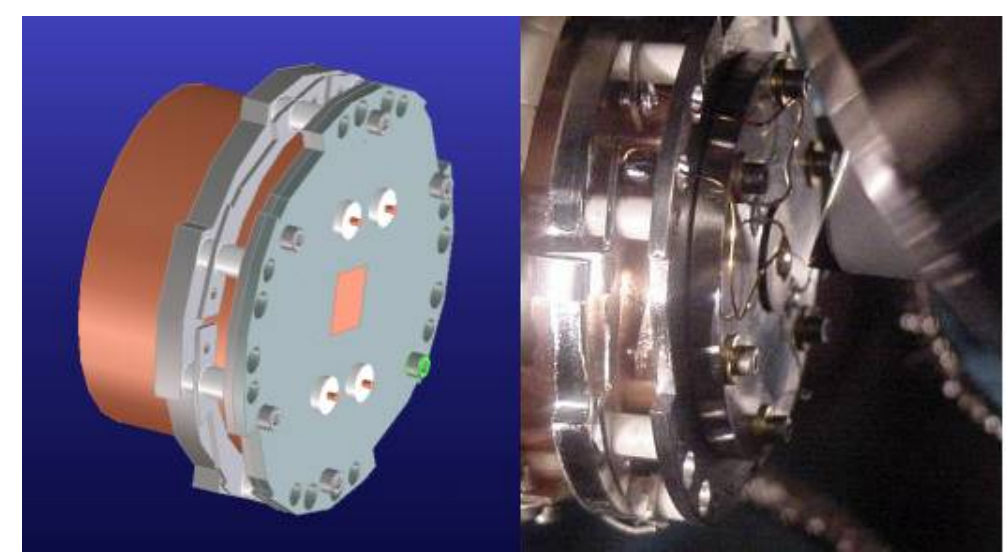
reversing the current flow. The upper temperature limit, given by the melting temperature of the solder used for the assembly of the Peltier element as well as by the epoxy used in construction, is about $100^{\circ}$ C. Using Peltier elements with high-temperature solder and high-temperature epoxies could increase this limit to about $200^{\circ} \mathrm{C}$.

During experiments, the sample dock is maintained at a constant temperature above the dew point, providing a sink for the heat rejected by the Peltier element. The dock temperature is controlled between $-25^{\circ}$ and $+25^{\circ} \mathrm{C}$ by a recirculating chiller using ethanol as a working fluid ${ }^{63}$. At the maximum power of $4 \mathrm{~W}(0.9 \mathrm{~A})$ in vacuum the sample can be cooled $\sim 40^{\circ}$ below the dock temperature, or more than $50^{\circ} \mathrm{C}$ if an indium shim is present in the plate-dock contact. The thermal time constant is about $60 \mathrm{~s}$, allowing for accurate temperature control. There is a small change in sample temperature at constant current when gas is admitted to the analysis chamber. Adding $80 \mathrm{~Pa}$ of $\mathrm{CO}_{2}$ at constant Peltier current raised the sample temperature from $-16^{\circ}$ to $-14^{\circ} \mathrm{C}$ in one test. 


\section{Experimental Methods and Constraints for Synchrotron based APPES}

\section{The role of the gas phase in APPES measurements}

Since the incident $\mathrm{x}$-rays do not only irradiate the sample surface, but also the gas phase in front of the sample surface, gas phase peaks are also observed in the PES spectra, usually at partial pressures $>1$ $\mathrm{Pa}$. In most cases the core levels of the gas phase species are shifted by several eV to higher BE compared to peaks from the condensed species ${ }^{18}$, and therefore gas phase peaks usually do not interfere with the observation of the spectrum from the surface. In cases were gas phase peaks overlap with the signal of the surface the gas phase peaks can be shifted away from the surface peaks by applying a negative bias to the sample, as described in Ref. 22.

Gas phase peaks may be used to determine the gas phase composition in, e.g., heterogeneous catalytic experiments. This may provide more accurate information about the gas phase composition than mass spectrometry, since APPES measures the gas phase right in front of the surface part that is simultaneously measured in the spectra. Gas phase signals can also be used as intrinsic standards for the relative sensitivity for different elements in PES. For instance the relative $\mathrm{C} / \mathrm{O}$ sensitivity can be determined from measurements of $\mathrm{CO}$ or $\mathrm{CO}_{2}$ gas phase peaks. In experiments on insulating samples the ionization of the gas phase by the incident x-rays produces secondary electrons that reduce charging of the surface. This is in particular relevant since the use of "flood guns" for charge compensation under pressures over $10^{-3} \mathrm{~Pa}$ is not possible.

\section{Contaminations in APPES experiments}

Conventional surface science experiments are performed under UHV conditions in part to avoid unwanted sample contamination. In APPES experiments, with pressures many orders of magnitude higher than UHV, contamination of the surface is more difficult to avoid. Contamination originates both from impurities in the gas source, as well as replacement of contaminants from the walls of the experimental chamber upon introduction of a gas. Assuming that the concentration of the impurities in the gas source is $1 \mathrm{ppm}$, the partial pressure of the contaminant at $100 \mathrm{~Pa}$ total pressure is $10^{-4} \mathrm{~Pa}$. If the sticking coefficient of the gas molecules on the substrate is just 0.01 , then a monolayer of contamination will form on the substrate in 100 seconds. Therefore, the amount and type of contaminants, in particular hydrocarbons, has to be monitored at all times during APPES experiments. This contamination problem is less severe in APPES experiments on liquids, where constantly refreshed sample surfaces can be prepared in a variety of ways, as discussed in the introduction. 


\section{Applications to Catalysis and Environmental Chemistry}

Catalysis and the environmental sciences are areas that can benefit enormously from the application of APPES, and were the direct motivation for the development of APPES. We now illustrate its capabilities with two recent examples, one in environmental sciences and one in catalysis. Many more examples can be found in recent reviews ${ }^{64},{ }^{65}$ and in original papers from research groups that use the APPES instruments at the $\mathrm{ALS}^{66}$ and BESSY ${ }^{67}$ synchrotron facilities.

The first example concerns the growth of water films on oxide surfaces. At a very basic level there is the question of the thickness and chemistry of the interfacial water layers as a function of the relative humidity. Surprisingly enough this apparently simple question has been answered only in very few instances. Part of the problem is the lack of spectroscopic techniques to measure the thickness of the water film in well-defined conditions and with assessment of the possible presence of contaminant material. XPS is naturally suited for this purpose. The photoelectrons emitted from the $\mathrm{O} 1 \mathrm{~s}$ core level

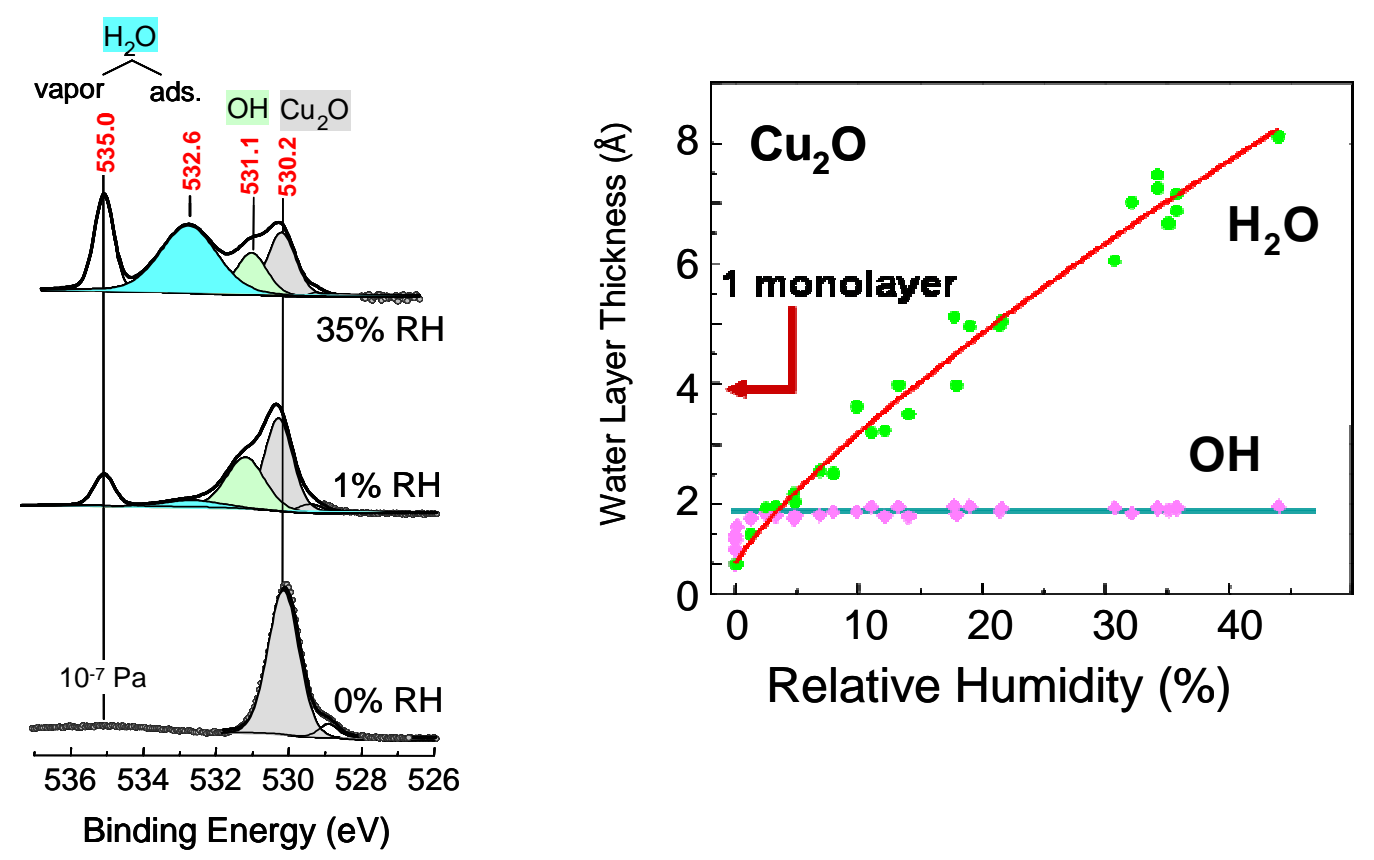

can provide an absolute measure of the amount of oxygen present, and thus water, even if other Ocontaining species are also present. This is because the chemical state of $\mathrm{O}$ determines the binding energy of its core electrons, allowing us to distinguish in many cases between various chemical forms. These include for example lattice $\mathrm{O}$ in the case of oxide substrates, hydroxyl $(\mathrm{OH})$ groups, molecular water, etc. This is illustrated in the spectra of figure 8 showing the $\mathrm{O}_{l s}$ region, for a photon energy of 
$735 \mathrm{eV}$, of $\mathrm{a} \mathrm{Cu}_{2} \mathrm{O}$ film grown on a copper foil at different relative humidities ${ }^{68}$. Various species can be easily distinguished in addition to the $\mathrm{O}$ in the $\mathrm{Cu}_{2} \mathrm{O}$ lattice. First hydroxyl groups form due to the dissociation of water at defect sites. Once these sites are saturated with $\mathrm{OH}$ the subsequent adsorption of water is molecular.

The graph on the right shows the thickness of the water layer as a function of relative humidity. As can be seen, at $45 \% \mathrm{RH}$ the film is approximately $0.7 \mathrm{~nm}$ thick, i.e. between two and three water layers. Similar experiments have been conducted in other oxide surfaces, including $\mathrm{TiO}_{2}(110), \mathrm{SiO}_{2}$ films on $\mathrm{Si}$ wafers, $\mathrm{Al}_{2} \mathrm{O}_{3}$ oxide films, $\mathrm{Fe}_{2} \mathrm{O}_{3}$ and $\mathrm{MgO} .^{69}$ Interestingly in all cases formation of hydroxyl groups is observed before the growth of molecular water films. This observation suggests that free H-bonds are needed at the surface for efficient binding of additional water. ${ }^{70}$ An important result is that the thickness is found to depend only on the relative humidity and not on the specific values of temperature and water partial pressure. Both isobar (constant pressure, changing temperature) and isotherm (constant temperature, changing pressure) curves collapse into a single curve when the $\mathrm{x}$-axis is converted to relative humidity. This is an important result because it indicates that the measured water layer thickness corresponds to the equilibrium value with the vapor phase.

The second example shows an application in the field of surface chemistry. The study addresses the question of the chemical composition of $\mathrm{Cu}$ and $\mathrm{Cu}_{2} \mathrm{O}$ in the presence of $\mathrm{CO}_{2}$ and $\mathrm{H}_{2} \mathrm{O}$, an interesting tribochemical system that plays an important role in the lifetime of contacts between copper brushes and the copper rotor in electrical motors ${ }^{71}$. The chemical reactions of copper with $\mathrm{CO}_{2}$ and $\mathrm{H}_{2} \mathrm{O}$ are also at the basis of many fundamental processes in catalysis and photochemistry. $\mathrm{Cu}$ is also used a catalyst in methanol synthesis and water gas shift reactions ${ }^{72,73,74}$, which also involve $\mathrm{CO}_{2}$ and/or $\mathrm{H}_{2} \mathrm{O}$.

The $\mathrm{Cu}-\mathrm{CO}_{2}-\mathrm{H}_{2} \mathrm{O}$ system was studied recently by Xingyi et al. ${ }^{75}$ at the ALS beamline 11.0.2 using

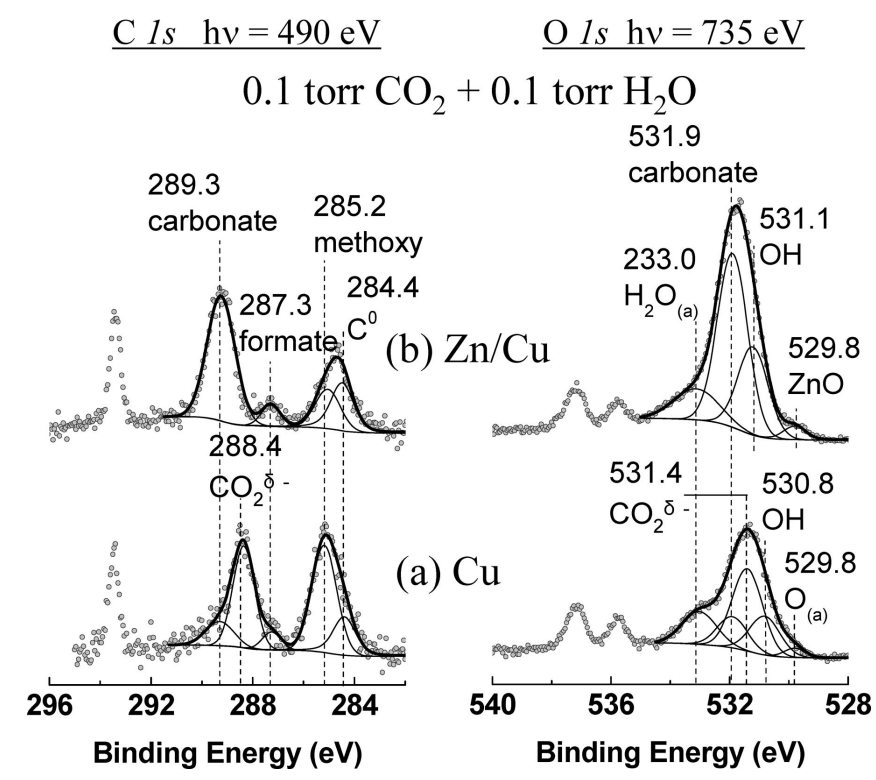
a polycrystalline foil that was cleaned in the preparation chamber described above. An evaporator in that chamber allowed also for the deposition of small amounts of $\mathrm{Zn}$, an important ingredient in catalytic 
systems and also used in the motor brushes as a structural element. The XPS data in the C and O 1s regions of the clean and $\mathrm{Zn}$ covered (0.1 monolayer) sample are shown in figure 9 . The spectra reveal the presence of several chemical species that are only stable in equilibrium with a $25 \mathrm{~Pa}$ of gas containing equal amounts of $\mathrm{CO}_{2}$ and $\mathrm{H}_{2} \mathrm{O}$. In pure $\mathrm{Cu}$ the species found include chemisorbed $\mathrm{CO}_{2}$ and methoxy $\left(\mathrm{CH}_{3}-\mathrm{O}-\right)$ as majority species, with smaller amounts of $\mathrm{OH}$, water, formate (COO-) and carbonate $\left(\mathrm{CO}_{3}{ }^{-}\right)$. While clean $\mathrm{Cu}$ is capable of activating $\mathrm{CO} 2$ to negatively charged $\mathrm{CO}_{2}{ }^{\delta-}$ species, which can further convert to carbonate, $\mathrm{Cu}_{2} \mathrm{O}$ produced by the oxidation of the $\mathrm{Cu}$ foil in oxygen gas, was found to be inactive toward $\mathrm{CO}_{2}$ adsorption at room temperature. The carbonate species undergoes further deoxygenation or reduction, yielding $C^{0}$ (a) and chemisorbed oxygen on the surface. The presence of 0.1 ML $\mathrm{Zn}$ on $\mathrm{Cu}$ facilitates carbonate formation while depleting the concentration of $\mathrm{CO}_{2}{ }^{\delta-}$ on the surface. In addition to the species observed in pure $\mathrm{CO} 2$, methoxy and formate are formed when $\mathrm{H}_{2} \mathrm{O}$ is coadsorbed, which then provides the hydrogen needed for the reaction.

\section{Conclusions}

APPES instrumentation has been developed at the LBNL and is now implemented in two Synchrotron Facilities, the ALS in Berkeley and Bessy in Berlin. The instrumentation is based on the simple idea of extracting the electrons from the gas environment at a distance from the originating surface that is comparable with the mean free path. While this idea was implemented from the very beginning of photoemission spectroscopy by K. Siegbahn and collaborators in Sweden, and later by other groups around the world, what makes the current APPES instruments unique is the combination of the differential pumping methods with electrostatic focusing at the apertures separating the various chambers. We have described the basic physics that influence APPES, including electron- gas interactions, electron optics and gas pumping constraints. Two examples were presented to illustrate the capabilities of the APPES in applications to environmental and surface chemistry sciences.

\section{Acknowledgements}

The authors would like to acknowledge the assistance of Ed Wong in the construction of the APPES-1 and APPES-2 systems. We would also like to thank Simon Mun for help at beamline 9.3.2, as well as Tolek Tyliszczak, Mary Gilles, and David Shuh for support at beamline 11.0.2. We gratefully acknowledge the contributions of Michael Hävecker, Klaus Ihmann, Evgueni Kleimenov, Axel KnopGericke and Robert Schlögl (Fritz Haber Institute, Berlin) during the design and construction phase of 
the APPES-2 system at the ALS. Financial support for the initial phase of the project was from an LDRD grant from the LBNL director. Subsequent funding was provided by the Director, Office of Science, Office of Advanced Scientific Computing Research, Office of Basic Energy Sciences, Materials Sciences and Engineering, and Chemical Sciences, Geosciences, and Biosciences Division of the U.S. Department of Energy under Contract No. DE-AC02-05CH11231. 


\section{Figure Captions}

Fig 1. APPES spectra of water vapor at pressures from 66.5 to $665 \mathrm{~Pa}$ at $569 \mathrm{eV}$ incident photon energy. The small peaks between 530 and $560 \mathrm{eV}$ kinetic energy are photoemission from the water $2 \mathrm{~b}_{1}{ }^{*}$, $4 a_{1}{ }^{*}, 1 b_{2}, 3 a_{1}$ and $1 b_{1}$ molecular orbitals, and the larger peaks below $500 \mathrm{eV}$ are the Auger KLL electrons from the relaxation of ionized $\mathrm{O}$ 1s core levels. The spectra are offset for visibility and have been scaled by pressure, so in the absence of electron-molecule scattering all would have the same intensity. Inelastic scattering reduces the relative peak intensity while increasing the inelastic background.

Fig 2. Experimental energy loss distribution for electrons scattering from gas-phase $\mathrm{H}_{2} \mathrm{O}$ molecules. Reproduced from Garcia and Blanco et al. ${ }^{42}$

Fig 3. Total, elastic and inelastic scattering cross-sections $\left(\AA^{2}\right)$ for gas-phase toluene $\left(\mathrm{C}_{7} \mathrm{H}_{8}\right)$ and water $\left(\mathrm{H}_{2} \mathrm{O}\right)$ as a function of energy. This figure was plotted from published data for water ${ }^{42}$ and toluene ${ }^{76}$. The black crosses show experimental measurements of APPES signal attenuation with water vapor pressure (see text).

Fig 4. Comparison of energy-dependent X-ray absorption cross-sections ${ }^{77}$ for light atoms $(\mathrm{C}, \mathrm{O})$ found in gas molecules and for some transition metal atoms relevant to catalysis.

Fig 5. Schematic of the APPES-2 vacuum system showing the sample, $x$-ray source and entrance to the APPES spectrometer.

Fig 6. CAD drawing of the copper sample dock, the base and the front face (exploded drawing) of the Peltier-cooled sample plate. The bayonet mounts and electrical contacts can be seen on the sample plate, the corresponding elements are not shown on the sample dock for clarity.

Fig 7. Peltier-cooled sample plate. The CAD sketch at left shows the front face with electrical feedthroughs and copper plug for sample mounting. The photo at right shows the plate in the APPES-2 system with a liquid water drop condensed on the sample.

Fig. 8. Adsorption of water on a $\mathrm{Cu}_{2} \mathrm{O}$ film with a thickness $\geq 1.5 \mathrm{~nm}$, prepared by oxidation of a $\mathrm{Cu}$ foil. O $1 s$ XPS spectra were acquired in vacuum (bottom), and at increasing relative humidity (RH) values. For clarity only the spectra corresponding to 1 and $35 \% \mathrm{RH}$ are shown. The spectra reveal the presence of various oxygen species, including lattice oxygen of $\mathrm{Cu}_{2} \mathrm{O}, \mathrm{OH}$ (adsorbed hydroxyl) and molecular adsorbed $\mathrm{H}_{2} \mathrm{O}$, on the surface. The peak at higher $\mathrm{BE}$ at $\sim 535 \mathrm{eV}$ is due to gas phase $\mathrm{H}_{2} \mathrm{O}$. 
The plot on the right shows the ratio of $\mathrm{OH}$ to lattice oxygen and the thickness of the adsorbed $\mathrm{H}_{2} \mathrm{O}$ layer as a function of relative humidity obtained by measuring the areas under the corresponding peaks.

Fig 9. Carbon and Oxygen 1s XPS spectra of (a) pure $\mathrm{Cu}$ and (b) $\mathrm{Zn} / \mathrm{Cu}(0.1 \mathrm{ML} \mathrm{Zn})$ in the presence of $13 \mathrm{PaCO} 2+13 \mathrm{~Pa} \mathrm{H}_{2} \mathrm{O}$ at room temperature. Two carbonaceous species, formate and methoxy are shown to form on both surfaces. Activated $\mathrm{CO}_{2}$ and carbonate species present in pure $\mathrm{CO} 2$ remain visible on each surface. In addition, molecularly adsorbed $\mathrm{H} 2 \mathrm{O}$ is also observed in both spectra. The presence of $\mathrm{Zn}$ makes carbonate the majority species on the surface. 


\section{References}

1. C. Lamberti, E. Groppo, G. Spoto, S. Bordiga and A. Zecchina, Adv. Catal. 51, 1 (2007).

2. G. Ewing, Chem. Rev. 106, 1511 (2006).

3. G. Rupprechter, Adv. Catal. 51, 133 (2007).

4. X. Wei, P. Miranda, R. Shen, Phys. Rev. Lett 86, 1554 (2001).

5. E.A. Raymond, G.L. Richmond, J. Phys. Chem. B 108, 5051 (2004).

6. S. Baldelli, C. Schnitzer, M.J. Shultz, D.J. Campbell, J. Phys. Chem. B 101, 10435 (1997).

7. $\quad$ P.B. Petersen, R.J. Saykally, Ann. Rev. Phys. Chem. 57, 333 (2006).

8. A. Knop-Gericke, M. Hävecker, Th. Schedel-Niedrig, R. Schlögl, Topics in Catalysis 10, 187 (2000).

9. G. Andersson, H. Morgner, Surf. Sci. 405, 138 (1998).

10. Y. Harada, S. Masuda, H. Ozaki, Chem. Rev. 97, 1897 (1997).

11. H. Morgner. Adv. At. Molec. Opt. Phys. 42, 387 (2000).

12. J. Hu, X.-d. Xiao, D.F. Ogletree, M. Salmeron, Science 268, 267 (1995).

13. H. Bluhm and M. Salmeron, J. Chem. Phys. 111, 6947 (1999).

14. A. Doeppenschmidt, M. Kappl, H.-J. Butt, J. Phys. Chem. B 102, 7813 (1998).

15. B.J. McIntyre, M. Salmeron and G.A. Somorjai. Catal. Lett. 39, 5 (1996).

16. B.L.M. Hendriksen, J.W.M. Frenken, Phys. Rev. Lett. 89, 046101 (2002).

17. A.M. Donald, Nature Materials 2, 511 (2003).

18. K. Siegbahn, C. Nordling, G. Johansson, J. Hedman, P.F. Heden, K. Hamrin, U. Gelius, T. Bergmark, L.O. Werme, R. Manne, Y. Baer, "ESCA applied to free molecules", 1969, NorthHolland Publishing Company.

19. H. Siegbahn, J. Phys. Chem. 89, 897 (1985).

20. H. Fellner-Feldegg, H. Siegbahn, L. Asplund, P. Kelfve, K. Siegbahn, J. Electron Spectrosc. Relat. Phenom. 7, 421 (1975).

21. H. Siegbahn, S. Svensson, M. Lundholm, J. Electron Spectrosc. Relat. Phenom. 24, 205 (1981).

22. H. Siegbahn, M. Lundholm, J. Electron Spectrosc. Relat. Phenom. 28, 135 (1982).

23. R. Moberg, F. Bökman, O. Bohman, H. Siegbahn, J. Chem. Phys. 94, 5226 (1991).

24. R. Moberg, F. Bökman, O. Bohman, H. Siegbahn, J. Am. Chem. Soc. 113, 3663 (1991).

25. H. Siegbahn, K. Siegbahn, J. Electron Spectrosc. Rel. Phenom. 2, 319 (1973). 
26. R.E. Ballard, S.L. Barker, G.G. Gunnell, W.H. Hagan, S.J. Pearce, R.H. West, J. Electron Spectrosc. Rel. Phenom. 14, 331 (1978).

27. R.E. Ballard, G.G. Gunnell, W.H. Hagan, J. Electron Spectrosc. Rel. Phenom. 16, 435 (1979).

28. H. Aulich, L. Nemec, L. Chia, P. Delahay, J. Electron Spectrosc. Rel. Phenom. 8, 271 (1976).

29. L. Nemec, H.J. Gaehrs, L. Chia, P. Delahay, J. Chem. Phys. 66, 4450 (1977).

30. I. Watanabe, J.B. Flanagan, P. Delahay, J. Chem. Phys. 73, 2057 (1980).

31. R.W. Joyner, M.W. Roberts, K. Yates, Surf. Sci. 87, 501 (1979).

32. H.J Ruppender, M. Grunze, C.W. Kong, M. Wilmers, Surf. Interf. Anal. 15, 245 (1990).

33. J. Pantförder, S Pöllmann, J.F. Zhu, D Borgmann, R. Denecke, H.-P. Steinrück, Rev. Sci. Instrum. 76, 014102 (2005).

34. B. Winter, R. Weber, W. Widdra, M. Dittmar, M. Faubel, I.V. Hertel, J. Phys. Chem. A 108, 2625 (2004).

35. B. Winter, R. Weber, I.V. Hertel, M. Faubel, P. Jungwirth, E.C. Brown, S.E. Bradforth, J. Am. Chem. Soc. 127, 7203 (2005).

36. D.F. Ogletree, H. Bluhm, G. Lebedev, C.S. Fadley, Z. Hussein, M. Salmeron, Review of Scientific Instruments 72, 3872 (2002).

37. H. Bluhm, M. Hävecker, K. Ihmann, E. Kleimenov, D. Teschner, D.F. Ogletree, M. Salmeron, A. Knop-Gericke, R. Schlögl, in prepration.

38. H. Bluhm, K. Andersson, T. Araki, K. Benzerara, G.E. Brown, J.J. Dynes, S. Ghosal, M.K. Gilles, H.-Ch. Hansen, J.C. Hemminger, A.P. Hitchcock, G. Ketteler, A.L.D. Kilcoyne, E. Kneedler, J.R. Lawrence, G.G. Leppard, J. Majzlam, B.S. Mun, S.C.B. Myneni, A. Nilsson, H. Ogasawara, D.F. Ogletree, K. Pecher, M. Salmeron, D.K. Shuh, B. Tonner, T. Tyliszczak, T. Warwick, T.H. Yoon, J. Electron Spectrosc. Relat. Phenom. 150, 86 (2006).

39. Nanoscale Technologies GmbH, Stuttgart, Germany. www.nascatec.com.

40. T. Tyliszczak, T. Warwick, A.L.D. Kilcoyne, S. Fakra, D.K. Shuh, T.H. Yoon, G.E. Brown, Jr., S. Andrews, V. Chembrolu, J. Strachan, Y. Acreman, Synchrotron Radiation Instrumentation 2003, AIP Conference Proceedings 705, 1356 (2004)

41. D. Attwood, W. Chao, E. Anderson, J. A. Liddle, B. Hartneck, P. Fischer, B. Schneider, M. Le Gros, C. Larabell, J. Biomed. Nanotech. 275 (2006). 
42. A. Munoz, J. C. Oller, F. Blanco, J. D. Gorfinkiel, P. Limao-Vieira and G. Garcia, Physical Review A 76052707 (2007).

43. The Physical Electronics hemispherical capacitor analyzer used in the APPS-1 system had a maximum acceptance of $\sim 7^{\circ}$. The SPECS Phoibos 150 analyzer used for APPES-2 had a maximum acceptance of $\sim 9^{\circ}$.

44. Ian W. Drummond, "XPS: instrumentation and Performance", in Surface Analysis by Auger and XPS, ed. David Briggs and John T. Grant, IM Publications 2003, Chichester, West Sussex, UK, ISBN 1901019047.

45. H. Bluhm, D.F. Ogletree, Ch. Fadley, Z. Hussain, and M. Salmeron, J. Phys.: Condens. Matter 14, L227 (2002).

46. F.G. Requejo, E.L.D. Hebenstreit, D.F. Ogletree, M. Salmeron, J. Catal. 226, 83 (2004).

47. Silson Ltd., Northampton, UK, www.silson.com.

48. Phoibos 150 analyzer, Specs GmbH, Berlin, www.specs.de.

49. Leybold TW 701, TW 250, and TW 70, Oerlikon Leybold Vacuum, Köln, Germany, www.oerlikon.com.

50. Drytel $100 \mathrm{C}$, Adixen, www.adixen-usa.com.

51. SRS RGA300, Stanford Research Systems, Sunnyvale, CA, www.thinksrs.com

52. MKS Instruments, Andover, MA, www.mksinst.com.

53. Thermionics, Port Townsend, WA, www.thermionics.com.

54. Transfer Engineering and Manufacturing, Inc., Fremont, CA, www.transferengineering.com.

55. AXUV 100 photodiode, International Radiation Detectors, Torrance, CA, www.ird-inc.com.

56. National Instruments, Austin, TX, www.ni.com.

57. Heat Wave Labs, Watsonville, CA; www.cathode.com.

58. G. Ketteler, D.F. Ogletree, H. Bluhm, H. Liu, E.L.D. Hebenstreit, M. Salmeron, J. Am. Chem. Soc. 127, 18269 (2005).

59. S. Günther, F. Esch, L. Gregoratti, A. Barinov, M. Kiskinova, E. Taglauer, H. Knözinger, J. Phys. Chem. B 108, 14223 (2004).

60. Design and construction due to D.E. Starr, Brookhaven National Laboratory, Upton, NY. 
61. G.E. Brown, Jr., V.E. Henrich, W.H. Casey, D.L. Clark, C. Eggleston, A. Felmy, D.W. Goodman, M. Grätzel, G. Maciel, M.I. McCarthy, K. Nealson, D.A. Sverjensky, M.F. Toney, J.M. Zachara, Chem. Rev. 99, 77 (1999).

62. Peltier source \& model

63. FTS systems series RS recirculating chiller, Stone Ridge, NY, www.ftssystems.com.

64. H. Bluhm, M. Hävecker, A. Knop-Gericke, M. Kiskinova, R. Schlögl, M. Salmeron, MRS Bulletin 32, 1022 (2007).

65. M. Salmeron, R. Schlögl, Surf. Sci. Rep. 63, 169 (2008).

66. F.G. Requejo, E.L.D. Hebenstreit, D.F. Ogletree and M. Salmeron. J. Catal. 226, 83 (2004).

67. H. Bluhm, M. Hävercker, A. Knip-Gericke, D. Teschner, E. Eleimenov, V.I. Bukhtiyarov D.F. Ogletree, M. Salmeron, and R. Schlögl. J. Phys. Chem. B. 108, 14340 (2004)

68 Xingyi Deng, Tirma Herranz, Christoph Weis, Hendrik Bluhm Miquel Salmeron. J. Phys. Chem. C. 112 (26) 9668-9672 (2008)

69. G. Ketteler, S.Yamamoto, H. Bluhm, K. Andersson, D.E. Starr, D.F. Ogletree, H. Ogasawara, A. Nilsson, M. Salmeron. J. Phys. Chem. C. 111, 8278 (2007)

70. M. Salmeron, H. Bluhm, M. Tatarkhanov, G. Ketteler, T.K. Shimizu, A. Mugarza, Xingyi Deng, T. Herranz, S. Yamamoto, A. Nilsson, Faraday Discussions, 2008, (DOI:: B806516K).

71 Slade, P. G. Electrical Contacts: Principles and Applications; Marcel Dekker: New York, 1999.

72 Chinchen, G. C.; Spencer, M. S.; Waugh, K. C.; Whan, D. A. J. Chem. Soc. Faraday Trans. 1987, 83, 2193.

73 Salmi, T.; Hakkarainen, R. Appl. Catal. 1989, 49, 285.

74 Waugh, K. C. Catal. Today 1992, 15, 51.

75. Xingyi Deng, A. Verdaguer, T. Herranz, Ch.D. Weiss, H. Bluhm, M. Salmeron. Langmuir 24, 9474 (2008).

76. G. Garcia, F. Blanco, A. Grau Carles, A. Grau Malonda, Applied Radiation and Isotopes, 60, 481, 2004.

77. Cross section data from the web site at the LBL Center for X-ray Optics, maintained by Eric Gullikson at www-cxro.lbl.gov, based partly on data from B. L. Henke, E. M. Gullikson and J. C. Davis, Nuclear Data Tables 54, 181 (1993). 